This item was submitted to Loughborough's Research Repository by the author.

Items in Figshare are protected by copyright, with all rights reserved, unless otherwise indicated.

\title{
Effects of hydrogen addition on high-pressure nonpremixed natural gas combustion
}

PLEASE CITE THE PUBLISHED VERSION

http://dx.doi.org/10.1080/00102202.2010.496381

PUBLISHER

(c) Taylor \& Francis

VERSION

AM (Accepted Manuscript)

LICENCE

CC BY-NC-ND 4.0

\section{REPOSITORY RECORD}

Wu, N., G.P. McTaggart-Cowan, W.K. Bushe, and Martin H. Davy. 2019. "Effects of Hydrogen Addition on High-pressure Nonpremixed Natural Gas Combustion”. figshare. https://hdl.handle.net/2134/8788. 
This item was submitted to Loughborough's Institutional Repository (https://dspace.lboro.ac.uk/) by the author and is made available under the following Creative Commons Licence conditions.

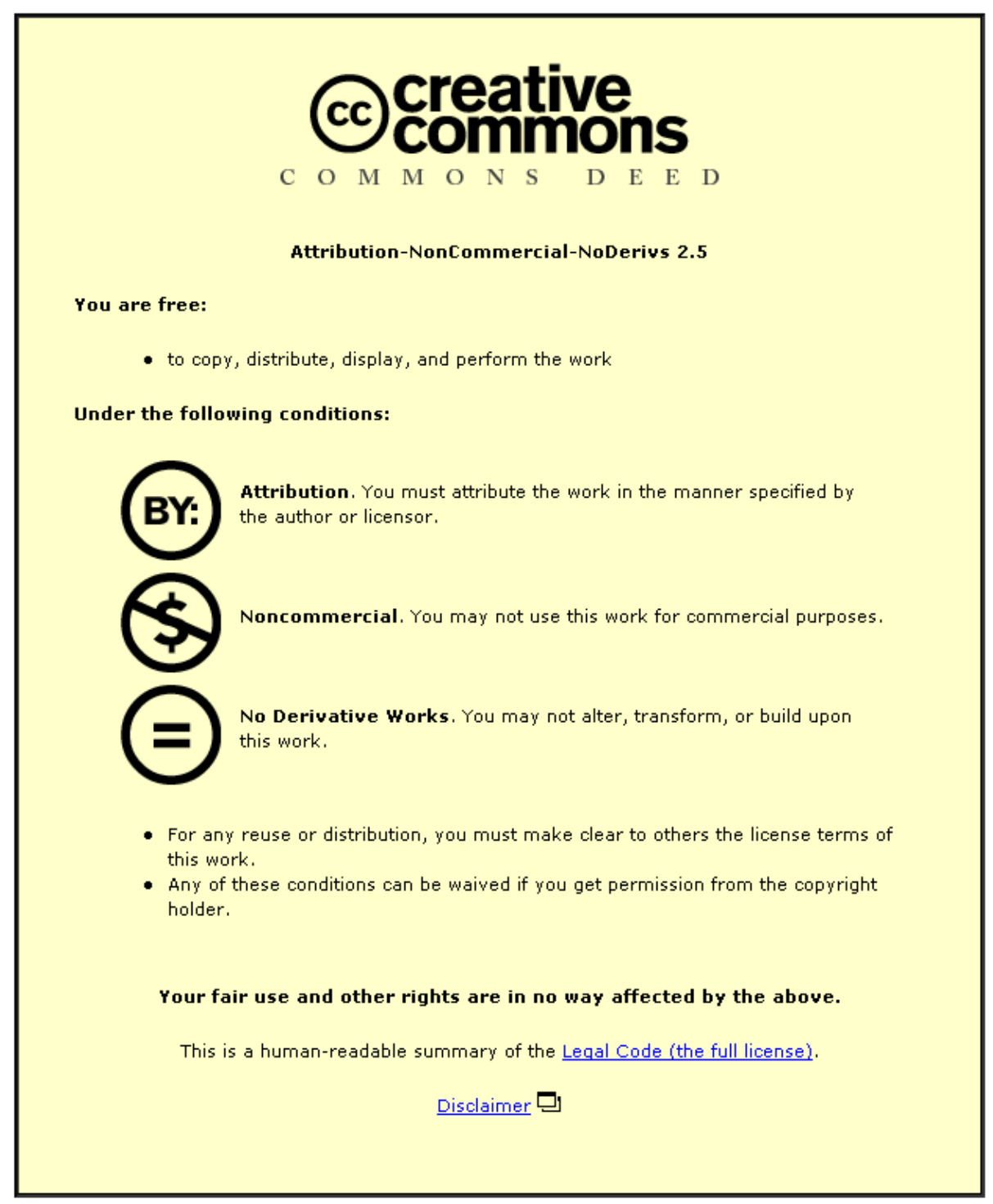

For the full text of this licence, please go to: http://creativecommons.org/licenses/by-nc-nd/2.5/ 


\title{
Effects of Hydrogen Addition on High-Pressure Non-Premixed Natural Gas Combustion
}

\author{
N. Wu', G.P. McTaggart-Cowan ${ }^{2}$, W.K. Bushe ${ }^{1}$, and M.H. Davy ${ }^{1 *}$ \\ ${ }^{1}$ Department of Mechanical Engineering, University of British Columbia, Vancouver, Canada \\ ${ }^{2}$ Wolfson School of Mechanical and Manufacturing Engineering, Loughborough University, UK
}

\begin{abstract}
The effects of hydrogen addition on the ignition and combustion of a high-pressure methane jet in a quiescent charge of high-temperature, medium-pressure air were investigated numerically and experimentally. Subsequently, the results of these two fundamental studies were applied to the interpretation of combustion and emissions measurements from a pilot-ignited natural gas engine fuelled with similar fuels. Whereas, under quiescent conditions, the influence of hydrogen addition on the auto-ignition delay time of the gaseous jet was small, a markedly greater effect was observed in the more complex environment of the research engine. Similarly, in the two fundamental studies, the addition of hydrogen to the methane fuel resulted in a reduction of $\mathrm{NO}_{x}$ emissions, whereas increased levels of $\mathrm{NO}_{x}$ emissions were observed from the engine, highlighting the difference between the auto-ignition and pilot-ignition process.
\end{abstract}

Key Words: Non-premixed jet; methane; hydrogen; auto-ignition; pilot-ignition engine

\section{Introduction}

Natural gas (NG) has long been considered one of the most promising alternative fuels for transportation applications. NG is inherently clean burning (compared with conventional gasoline and diesel fuel), is widely available, and is relatively inexpensive. Moreover, as NG is predominantly methane $\left(\mathrm{CH}_{4}\right)$, it has a low carbon/hydrogen ratio; emissions of $\mathrm{CO}_{2}$ are thus significantly less than traditional liquid hydrocarbon fuels. Hydrogen $\left(\mathrm{H}_{2}\right)$ is also receiving considerable attention as a potential transportation fuel, using either IC engines or other energy conversion technologies. Combining $N G$ and $\mathrm{H}_{2}$ as a fuel in a combustion system offers the

* Contact author: davy@mech.ubc.ca. Department of Mechanical Engineering, University of British Columbia, 2054-6250 Applied Science Lane, Vancouver, B.C., Canada, V6T 1Z4. Phone: (1) 604-822-8256 
potential to achieve significant near-term reductions in transport-related local air pollutant and greenhouse gas (GHG) emissions without requiring widespread deployment of a dedicated $\mathrm{H}_{2}$ infrastructure. This study aims to provide fundamental understanding of non-premixed blended $\mathrm{NG} / \mathrm{H}_{2}$ combustion, and to apply this knowledge to understand the factors influencing the combustion process in a heavy-duty gaseous fuelled engine.

Despite the benefits of gaseous fuelling of internal combustion engines, implementation remains problematic. Natural gas does not auto-ignite under the in-cylinder pressures and temperatures typically found in an internal combustion engine: accordingly, most currentgeneration NG engines are spark-ignited. While this method reliably ignites the gaseous fuel, the resultant engines suffer from efficiency penalties similar to those of typical gasoline-fuelled engines, including the need for throttling at part-load and retarded timing to avoid knock at full load. Furthermore, the low volumetric energy density of gaseous fuels means that, if the fuel is introduced into the air stream in the intake system (as opposed to in the cylinder), the displacement of air by the gaseous fuel significantly reduces full load power.

Pilot ignition provides an attractive alternative to spark ignition for gaseous fuels. Combined with direct (in-cylinder) injection of the fuel, pilot ignition offers the opportunity to operate gaseous fuelled engines more efficiently, with higher compression ratios and reduced pumping losses, while providing full load power similar to an equivalent liquid-fuelled engine. One such system, which has recently entered limited production, is manufactured by Vancouverbased Westport Innovations Inc. This system employs a dual-fuel injector, which injects a small quantity of diesel fuel late in the engine's compression stroke. Natural gas is injected into the cylinder (through separate injector holes) a short time later. The diesel fuel auto-ignites, which creates the required in-cylinder conditions to ignite the natural gas. Following the premixed combustion of the small amount of NG which has mixed with air to be within flammable limits prior to ignition, the bulk of the injected gas is burned as a non-premixed jet. A more thorough description of the combustion system and its normal operation can be found elsewhere (McTaggart-Cowan, 2006). 


\section{Previous Studies of Hydrogen-Enriched Methane Combustion}

A significant amount of research has been conducted investigating premixed methane/hydrogen auto-ignition and combustion. Initial shock tube studies of high-temperature ignition used methane/hydrogen/oxygen mixtures diluted with 90 percent argon. Lifshitz et al. (1971) used these results to propose a thermal-based theory explaining why hydrogen reduced ignition delay. Subsequently Cheng and Oppenheim (1984), using experiments for temperatures from 800 to $2000 \mathrm{~K}$ and pressures from 1 to $3 \mathrm{~atm}$, correlated ignition delay $(\tau)$ with the formula:

$$
\tau=\tau_{\mathrm{CH}_{4}}{ }^{(1-\varepsilon)} \tau_{\mathrm{H}_{2}}{ }^{\varepsilon}
$$

where $\varepsilon$ is the mole fraction of hydrogen in the fuel and $\tau_{\mathrm{CH} 4}$ and $\tau_{\mathrm{H} 2}$ and are the ignition delay times of pure methane and pure hydrogen under the same conditions. Huang et al. (2006) measured the ignition delay time of stoichiometric methane/hydrogen/air mixtures in a series of shock tube experiments at pressures from 16 to $40 \mathrm{~atm}$ and temperatures from 1000 to $1300 \mathrm{~K}$. The addition of hydrogen was seen to promote ignition more significantly at higher temperatures and lower pressures. More recently, Petersen et al. (2007) used the reflected shock technique to measure ignition delay times from methane/hydrogen/air mixtures under lean burn $(\phi=0.5)$ combustion conditions over a range of pressures near $21 \mathrm{~atm}(18.2-25.1 \mathrm{~atm})$ and temperatures ranging from $1141 \mathrm{~K}$ to $1553 \mathrm{~K}$. In agreement with the earlier work of Cheng and Oppenheim, the effect of hydrogen addition on ignition delay was found to increase with increasing amounts of hydrogen in the blend-20\% $\mathrm{H}_{2}$ addition decreased the ignition delay by a factor of 3 while the addition of $40 \% \mathrm{H}_{2}$ resulted in a nearly 10 fold decrease in ignition delay compared to the base methane fuel. Similarly, Herzler and Naumann (2009) used a high-pressure shock tube to determine the ignition delay times of methane/ethane/hydrogen mixtures (with an oxidizer blend of $\mathrm{O}_{2}$ and $\left.\operatorname{Ar}[21 \% / 79 \%]\right)$ at nominal test pressures of 1,4 and 16 bar and a temperature range of 900-1800 K. Again, the ignition was observed to become faster with increasing hydrogen content. However, one notable feature of Herzler and Naumann's work was the observation of a complex pressure dependency for the ignition delay of mixtures containing in excess of $40 \%$ hydrogen. Gersen et al. (2008) measured the ignition delay time of methane/hydrogen mixtures under 
stoichiometric conditions at pressures between 15 and 70 bar, and temperatures between 950 and $1060 \mathrm{~K}$ using a rapid compression machine. The results of Gersen et al. support the hypothesis that the ignition delay time can be related quantitatively to the hydrogen mole fraction in the fuel via equation (1) as suggested by Cheng and Oppenheim. Gersen and co-workers results also show strong agreement with the observations by Huang et al. (2006) that the effect of hydrogen in promoting ignition increases with temperature and decreases with pressure. Other fundamental premixed combustion studies have indicated that the preferential diffusion of hydrogen in a turbulent combustion event results in a higher flame propagation rate, even when the laminar flame speed is constant (Kido et al. 2002). The presence of hydrogen in the lean premixed flame also provides greater resistance to stretch, resulting in fewer extinction events, and increases the concentration of $\mathrm{H}, \mathrm{OH}$, and $\mathrm{O}$ radicals (Gauducheau et al. 1998). It has been suggested that the presence of more $\mathrm{OH}$ may contribute to the more rapid oxidation of the methane, and that using $20 \%$ hydrogen in methane can increase peak $\mathrm{OH}$ radical concentrations by as much as $20 \%$ (Larsen and Wallace, 1997; Schefer, 2003).

The non-premixed combustion of hydrogen/methane blends has not been studied as extensively. In a low-pressure, low-temperature co-flow burner experiment, Karbasi and Wierzba (1998) found that adding hydrogen to either the fuel or oxidizer increased flame speeds and enhanced mixing, improving non-premixed combustion stability. Differences in fuel-stream density with hydrogen addition were found to be secondary (Karbasi and Wierzba, 1998; Law and Kwon, 2004). The higher diffusivity of the hydrogen increased flame thickness under partially-premixed conditions (Naha and Aggarwal, 2004). In industrial gas turbines and boilers, hydrogen addition was found to enhance prompt nitric oxide (NO) formation (due to high $\mathrm{H}$ and $\mathrm{OH}$ radical concentrations) while flame stability was improved (Rortveit et al. 2002). Fotache et al. (1997) studied the ignition promoting effects of hydrogen in a non-premixed counter-flow methane/hydrogen/air jet. These results suggested that for hydrogen concentrations below $30 \%$ by volume, the $\mathrm{H}$ radicals enhance methane ignition, while above $30 \%$ hydrogen ignition dominates and the delay is independent of the relative methane/hydrogen concentration. 
With regard to internal combustion engines, the literature indicates that adding hydrogen to natural gas in premixed charge spark-ignition engines has a number of positive effects, most notably; extension of the lean combustion limit (Sierens and Rosseel, 2000; Collier et al. 2005), enhancement of the combustion rate and a reduction in ignition delay (Swain et al. 1993; Karim et al. 1996). Flame stability in the presence of exhaust gas recirculation (EGR) is also improved at all air-fuel ratios (Allenby et al. 2001; Larsen and Wallace, 1997). With respect to emissions, hydrogen addition can result in reduced $\mathrm{NO}_{x}$ emissions by allowing the engine to operate at leaner air-fuel ratios (Munshi et al. 2004); however, at a given air-fuel ratio $\mathrm{NO}_{\mathrm{x}}$ emissions are increased by hydrogen because of its higher flame temperature (Sierens and Rosseel, 2000; Collier et al. 2005). The amount of hydrogen in the fuel influences its impact on the combustion process in spark-ignited engines. Above $30 \%$ (by volume), the reduced charge energy density and higher potential for knock are substantial handicaps with little benefit in emissions or stability (Larsen and Wallace, 1997; Bauer and Forest, 2001).

There is less information available in the literature regarding the effect of hydrogen addition on the performance and emissions of natural gas fuelled combustion engines that utilize a non-premixed combustion strategy. The limited data available does suggest that the addition of hydrogen to the gaseous fuel improves ignitability and improves combustion stability, leading to significant reductions in emissions of combustion by-products including $\mathrm{CO}, \mathrm{HC}$, and $\mathrm{PM}$. However, $\mathrm{NO}_{\mathrm{x}}$ emissions are increased as a result of higher combustion temperatures (McTaggart-Cowan et al. 2009a).

\section{The Current Work}

In the current work, experimental results from two separate research facilities are combined with numerical simulations to investigate the effects of hydrogen addition on nonpremixed methane combustion at both the fundamental and the applied level. At the fundamental level, studies in a shock tube facility equipped with a gaseous fuel injection system provides improved understanding of hydrogen addition on non-premixed methane jet ignition and combustion. The results from the shock tube are compared to numerical simulations to provide a more comprehensive understanding of the effects of hydrogen addition on a non-premixed 
combustion event. At an applications level, a single-cylinder research engine provides indications of the implications of these findings on pollutant formation and combustion in a heavy-duty engine.

\section{Experimental Set-ups and Methods}

\subsection{Shock Tube}

The design and operation of the shock tube used in this work has been described previously (Huang et al. 2004, 2006; Sullivan et al. 2006; Wu et al. 2007). The stainless steel shock tube is $7.90 \mathrm{~m}$ long ( $3.11 \mathrm{~m}$ driver section and $4.79 \mathrm{~m}$ driven section) with an inside diameter of $5.9 \mathrm{~cm}$. The facility employs a reflected shock wave technique (Gaydon and Hurle, 1963) to preheat and compress a charge of Praxair medical grade air (the driven gas). Reflection of the shock wave from the test-section end wall generates a quiescent, high temperature region into which the gaseous fuel is injected. Four flush-mounted dynamic pressure transducers measure the incident shock velocity. Using this velocity, the test region temperature and pressure (after the passing of the reflected shock) are determined by solving the 1-D conservation equations for mass, momentum, and energy across the shock wave. Perfect gas behaviour is assumed and temperature-dependent fluid thermal properties are accounted for. The uncertainties in the calculated temperature and pressure are about $1-2 \%$ and $3-4 \%$, respectively, as discussed elsewhere (Huang et al. 2004). Through careful tailoring, effective runtimes of 4-5 ms are achieved with nearly constant post-reflected shock pressure and temperature conditions prior to the fuel injection. Fuel is injected along the shock tube axis into the heated and compressed air using a well-characterized single-hole, natural gas injector with $0.275 \mathrm{~mm}$ diameter orifice (Westport J43P2).

The ignition of the fuel jet and the subsequent combustion event is monitored optically through quartz windows $(2 \mathrm{~cm} \times 20 \mathrm{~cm})$ in the combustion zone, as well as with high-speed pressure transducers. A high frame rate CMOS-based digital camera (Vision Research Phantom v7.1 equipped with a $50 \mathrm{~mm}$ F/1.2 Nikon lens) measures the natural flame luminosity as well as blackbody radiation from any particles in the shock tube. For this work, the camera was operated at a frame rate of approximately 31,000 frames/second with an effective integration time of $1 \mu \mathrm{s}$ 
per frame and a nominal imaging resolution of $0.2 \mathrm{~mm} \times 0.2 \mathrm{~mm}$ per pixel. The pixel sensitivity is approximately flat for light wavelengths from 400 to $700 \mathrm{~nm}$ with relatively sharp roll-offs at 400 and $800 \mathrm{~nm}$. Light imaged in these experiments was depth of field integrated. A schematic of the shock tube setup is shown in Figure 1.

The fuel injector, the data acquisition system, the intensified CCD camera, and the HS video camera were triggered simultaneously by the rising edge of the incident shock wave as it passed the piezoelectric pressure transducer closest to the shock tube endplate. This triggering arrangement ensures that the first introduction of fuel into the shock tube (Start of Fuelling, SOF) occurs shortly after constant pressure and temperature conditions have been established in the experimental section. Earlier injector characterization tests, detailed in Wu (2007), found the mean injection delay of the fuel injector to be $0.311 \mathrm{~ms}$ with a standard error of approximately 400 $\mu s$ at a pressure ratio of 4 -the value used in the present study. Thus, the timing of the first appearance of fuel from the injector nozzle (SOF) is estimated as $0.311 \mathrm{~ms} \pm 78 \mu \mathrm{s}(95 \%$ confidence interval) after the start of injection (SOI) - where SOI in the refers to the commanded start of injection.

\subsection{Single Cylinder Research Engine (SCRE)}

The single cylinder research engine used in the present study and it's associated test cell and instrumentation have been described in detail in previous works by McTaggart-Cowan et al. (2003), and McTaggart-Cowan (2006). The base engine is a Cummins ISX series heavy-duty model that has been modified for single cylinder operation and equipped with a prototype version of Westport Innovations' HPDI ${ }^{\mathrm{TM}}$ direct-injection natural-gas combustion system. Table 1 details the engine configuration.

Table 1: Engine and injector specifications

\begin{tabular}{|l|l|}
\hline Engine & Cummins single cylinder 4-stroke, 4-valve \\
\hline Fuelling & Direct injection; diesel pilot, gaseous main fuel \\
\hline Displacement (/cylinder) & $2.5 \mathrm{~L}$ \\
\hline Compression Ratio & $17: 1$ \\
\hline Bore/Stroke/Connecting Rod Length & $137 / 169 / 261 \mathrm{~mm}$ \\
\hline Injector & Westport Innovations Inc. dual-fuel concentric needle \\
\hline \multicolumn{1}{|c|}{ Injection control } & Separate diesel and natural gas solenoids \\
\hline \multicolumn{1}{|c|}{ Injector holes } & 7 pilot, 9 gas \\
\hline \multicolumn{1}{|c|}{ Injection angle } & $18^{\circ}$ below fire deck \\
\hline
\end{tabular}


The engine facility is fully instrumented, with measurements of air and fuel flow (both diesel pilot and gaseous main fuel) as well as exhaust gas composition (AVL CEB-NA emissions bench). The gaseous fuel flow measurement uses a coriolis-force mass flow sensor, and hence is insensitive to changes in gaseous fuel composition. The combustion process is monitored using a high-speed water-cooled in-cylinder pressure transducer (AVL QC33C) in conjunction with a $12^{\circ}$ crank-angle encoder to identify the piston location. Figure 2 shows a schematic of the engine test facility.

\section{Experimental Test Conditions}

\subsection{Shock Tube}

Two series of tests were conducted in the shock tube. The first series of tests examined the effect of hydrogen addition on run-to-run variability. 20 repeat experiments were performed at a pre-combustion temperature $\left(T_{\circ}\right)$ of $1300 \mathrm{~K}$ and an injection pressure $\left(\mathrm{P}_{\mathrm{i}}\right)$ of 120 bar for each of two fuel compositions-methane $(99.97 \%$ purity) and a $80 / 20$ methane/hydrogen blend (\% by volume). The commanded injection duration was fixed at $1.0 \mathrm{~ms}$ for both series of tests. The second series of tests considers the effect of pre-combustion temperature on ignition and combustion of the two fuels in the range $1200-1400 \mathrm{~K}$. At least 3 replications were carried out for each pre-combustion temperature condition for each fuel blend in this series. Table 2 details the operating conditions and sample size for shock tube experiments reported herein.

Table 2: Operating conditions and sample size for shock tube experiments

\begin{tabular}{|c|c|c|c|c|}
\hline Fuel injector pressure, $\mathrm{P}_{\mathrm{i}},(\mathrm{bar})$ & \multicolumn{4}{|c|}{120} \\
\hline Fuel injection duration (ms) & \multicolumn{4}{|c|}{1.0} \\
\hline Pre-combustion pressure, $\mathrm{P}_{0}$, (bar) & \multicolumn{4}{|c|}{30} \\
\hline Fuel - $\% \mathrm{H}_{2}$ by volume & \multicolumn{2}{|c|}{0} & \multicolumn{2}{|c|}{20} \\
\hline Fuel energy density $\left(\mathrm{MJ} / \mathrm{m}^{3}\right)$ & \multicolumn{2}{|c|}{32.7} & \multicolumn{2}{|c|}{28.06} \\
\hline Fuel Hydrogen : Carbon mole ratio & \multicolumn{2}{|c|}{4.0} & \multicolumn{2}{|c|}{4.5} \\
\hline Experimental series & 1 & 2 & 1 & 2 \\
\hline Pre-combustion temperature, $\mathrm{T}_{0},(\mathrm{~K})$ & 1300 & $1200-1400$ & 1300 & $1200-1400$ \\
\hline Sample size & 20 & 16 & 20 & 14 \\
\hline
\end{tabular}

\subsection{Engine}


The effects of using a hydrogen-blended fuel in the direct-injection engine were investigated at a fixed operating condition as indicated in Table 3. Note that this operating condition is generally representative of a steady-state cruising mode for a heavy-duty engine; the use of moderate levels of EGR maintains relatively low levels of $\mathrm{NO}_{\mathrm{x}}$ without degrading the combustion event.

Table 3: Engine operating conditions and fuel composition

\begin{tabular}{|c|c|c|c|}
\hline Speed (RPM) & \multicolumn{3}{|c|}{1200} \\
\hline Indicated Power (kW) [\% load] & \multicolumn{3}{|c|}{$35[75 \%]$} \\
\hline Indicated Mean Effective Pressure (bar) & \multicolumn{3}{|c|}{13.5} \\
\hline Fuel-oxygen equivalence ratio & \multicolumn{3}{|c|}{0.6} \\
\hline Gaseous Fuel Pressure (MPa) & \multicolumn{3}{|c|}{21} \\
\hline EGR (mass \%) & \multicolumn{3}{|c|}{30} \\
\hline Combustion Timings (50\% IHR) & \multicolumn{3}{|c|}{$0,5,10,15^{\circ} \mathrm{CA}$ after top dead centre (TDC) } \\
\hline Fuel - $\% \mathrm{H}_{2}$ by volume & 0 & 15 & 35 \\
\hline Fuel energy density $\left(\mathrm{MJ} / \mathrm{m}^{3}\right)$ & 32.7 & 29.2 & 24.6 \\
\hline Fuel Hydrogen : Carbon mole ratio & 4.0 & 4.35 & 508 \\
\hline
\end{tabular}

Testing was carried out using three fuel compositions over a range of combustion timings. Natural gas $\left(>96 \% \mathrm{CH}_{4}\right)$ was used as the base fuel, and was blended with $15 \%$ and $35 \%$ (by volume) hydrogen. The diesel pilot contributed $5 \%$ of the total fuel energy for all test conditions. The compositions of the gaseous fuel blends were verified using gas chromatography. For each fuel blend, four combustion timings were tested, to provide comparison over a range of in-cylinder conditions while maintaining a constant fuel-oxygen equivalence ratio. The mid-point of the heat release rate $(50 \% \mathrm{lHR})$ was used as the combustion timing control variable: the timing was controlled by adjusting the start-of-injection (SOI) of the pilot fuel. The gaseous (main fuel) injection started $1.0 \mathrm{~ms}$ after the diesel injection finished. Despite variations in ignition delay and combustion rate with hydrogen addition to the fuel, the commanded SOI differed by less than $3^{\circ} \mathrm{CA}$ between methane and $35 \% \mathrm{H}_{2}$ combustion for all the combustion timings investigated.

\subsection{Numerical Simulation}

To elucidate the effect of hydrogen addition on the auto-ignition delay of methane fuel, a non-premixed counter-flow diffusion flame of methane blended with different amounts of hydrogen and air was simulated using the FlameMaster software package developed by Pitsch (n.d.). FlameMaster solves the flamelet equation, which is equivalent to the first-moment 
Conditional Moment Closure (CMC) approach for a homogenous, isotropic flow. The kinetic mechanisms adopted for the simulation of methane and methane/hydrogen oxidization in this study were those originally proposed by Huang et al. $(2004,2006)$. The ignition delay was defined as the time from the start of the simulation (which may be thought of as analogous to the first introduction of fuel in the shock tube) until the first abrupt increase in the normalized temperature field:

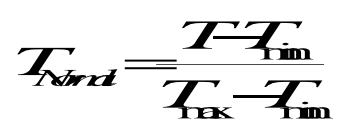

where $T_{\min }$ and $T_{\max }$ are, respectively, the minimum temperature and maximum temperatures at each mixture fraction.

\section{Results and Discussion}

\subsection{Fundamental Combustion Study (Shock Tube and Modelling Results)}

\subsubsection{Ignition Delay}

Table 4 shows the predicted effect of hydrogen addition on the ignition delay of methane in a non-premixed counter-flow diffusion flame where the oxidizer (air) temperature and ambient pressure are chosen to match the nominal pre-combustion temperature and pressure of the shock tube experiments ( $1300 \mathrm{~K}$ and 30 bar, respectively). The computations predict substantial decreases in ignition delay time with the addition of relatively modest quantities of hydrogen to the base methane fuel (a 13\% and 32\% reduction for the addition of, respectively, $10 \%$ and $20 \%$ by volume hydrogen).

Table 4: Ignition delay of methane with hydrogen addition predicted by FlameMaster (fuel temperature $300 \mathrm{~K}$, oxidizer temperature $1300 \mathrm{~K}$, pressure $30 \mathrm{bar}$ )

\begin{tabular}{|c|c|}
\hline Fuel $-\% \mathrm{H}_{2}$ by volume & Predicted Ignition Delay, $\mathrm{t}_{d \text { _ign }},(\mathrm{ms})$ \\
\hline 0 & 0.429 \\
\hline 10 & 0.375 \\
\hline 20 & 0.293 \\
\hline
\end{tabular}

The results from the shock tube do not show as significant a reduction in auto-ignition 
delay time with hydrogen addition as that predicted by the FlameMaster simulations. The mean ignition delay time in the shock tube, calculated from 20 repeat tests, was found to decrease by only $7 \%$ with the addition of $20 \%$ hydrogen as opposed to the $32 \%$ decrease seen in the FlameMaster simulations. A summary of the ignition delay data from the shock tube is shown in Table 5.

Table 5: Summary of shock tube ignition delay data at pre-combustion temperature and pressure of $1300 \mathrm{~K}$ and 30 bar (20 repeat tests)

\begin{tabular}{|c|c|c|c|c|c|}
\hline Fuel $-\% \mathrm{H}_{2}$ by volume & Min $(\mathrm{ms})$ & Max $(\mathrm{ms})$ & Mean $(\mathrm{ms})$ & Std Dev $(\mathrm{ms})$ & COV \\
\hline 0 & 0.465 & 0.901 & 0.736 & 0.113 & $15 \%$ \\
\hline 20 & 0.471 & 0.887 & 0.687 & 0.110 & $16 \%$ \\
\hline
\end{tabular}

There are several important points of note regarding the shock tube data, its interpretation, and the validity of comparison with the numerical results. Firstly, there is significant scatter in the data as evidenced by the high values of the coefficient of variation (COV) of the measured ignition delay for both fuels $(\mathrm{COV}=15 \%$ for methane, and $\mathrm{COV}=16 \%$ for methane/hydrogen blend). A large amount of scatter is also seen in the shock tube data for the variation of ignition delay with pre-combustion temperature in Figure 3 and, in fact, significant scatter is characteristic to all of the non-premixed combusting jet data obtained from the UBC shock tube. This topic therefore merits further discussion.

There are potentially three significant contributors to the large variations in ignition delay seen in the shock tube work. Firstly, there is the experimental technique itself. It is well known that the repeatability of shock tube experiments is not ideal and that there will be minor variations in pressures and temperatures from shock experiment to shock experiment (Gauthier et al., 2004; Vasu et al., 2008); secondly, there is the stochastic nature of the chemical reaction and thirdly, there is the inherent randomness associated with turbulent mixing in the developing jet.

With respect to the experimental technique, we have considered the likely magnitude of the variation in pre-combustion pressure and temperature and their expected influence on the ignition delay of a non-premixed jet in a previous work (Wu et al., 2010). The literature indicates 
that the ignition delay of a turbulent jet injected into a quiescent charge decreases with increasing pre-combustion temperature at the rate of approximately $0.0045 \mathrm{~ms} / \mathrm{K}$ (Wu et al., 2010), while showing only weak dependency on pressure (Fraser et al., 1991). In our referenced work, a series of 140 shock tube experiments were performed at nominally identical conditions of precombustion pressures and temperatures (respectively, 30 bar and $1300 \mathrm{~K}$ - identical conditions to those of the present study). The range of calculated pre-combustion temperatures in this 140 sample data set was $35 \mathrm{~K}$. Allowing the maximum uncertainty in the calculated temperature and assuming the aforementioned value for the temperature sensitivity would then lead to an expectation that the measured ignition delays should fall into a $0.2835 \mathrm{~ms}$ wide range band. The range of the ignition delay results shown in Table 5 substantially exceeds this value $(0.436 \mathrm{~ms}$ for methane and $0.416 \mathrm{~ms}$ for the methane/hydrogen blend). Accordingly, we reject the hypothesis that the scatter in the data is merely an artifact caused by the experimental method.

Accepting that there is a significant component of the observed variation in ignition delay that is a true reflection of the stochastic nature of the ignition process, the scatter in the ignition delay data from the shock tube experiments is simultaneously obstructive and educational. With respect to the analysis of the data shown in Table 5 (which considers the effects of hydrogen addition on ignition delay at a fixed pre-combustion pressure and temperature), the large run-torun variability in the data combined with the relatively small sample size (20 experiments) means that the statistical power of the experiments is insufficient to reliably draw conclusions from the observed differences in the mean ignition delay time. Analysis of variance (ANOVA) techniques indicate that the difference in the mean ignition delay times between the $0 \%$ and $20 \%$ hydrogen fuels is not statistically significant: the P-value (probability of the two results being sampled from the same data set) is 0.172 . Note that for all the ANOVA analyses presented herein, the a-priori decision was made to accept a $5 \%$ probability of making a type-I statistical error (identifying a significant difference when one is not present); hence only P-values below 0.05 are considered to identify a statistically significant difference between the mean values.

Returning now to Figure 3, which shows both the shock tube data (Figure 3a) and the FlameMaster predictions (Figure3b) for the variation of ignition delay with pre-combustion 
temperature, it is interesting to note that the scatter in the measured ignition delay data shown in Figure $3 a$ is reduced at higher temperatures. To understand the causes of the reduced scatter it is useful to conceptualize the total ignition delay time as being the sum of two nominally independent components as was first suggested by Bi and Agrawal (1998). The first component, which is equally applicable to premixed and non-premixed systems, is that due to the chemical reaction. The second component, which is specific to non-premixed systems, relates to the time necessary for the fuel and oxidant to mix and create a locally combustible mixture with a sufficiently favourable strain rate to facilitate auto-ignition. Bi and Agrawal (1998) referred to these two components as, respectively, the "kinetic" and "physical" components of the ignition delay. Note that in the present work both components are inherently stochastic processes. The stochastic nature of the chemical process is described by Frisque et al. (2006) in a study on premixed combustion as follows, "Autoignition as a macroscopic phenomenon is a result of a sequence of many events-collisions and reactions-on the microscopic scale. Each individual autoignition process consists of its particular chain of events; it is not the repetition of only one possible sequence". With regard to the physical delay in the present application, each realization of the jet starting and penetration process yields different strain histories and mixture fraction histories, some of which provide more favourable conditions for kernel formation than do others. As the pre-combustion temperature is increased the relative contributions of these two components to the overall ignition delay will change. The effects of changing the oxidizer temperature between $1200 \mathrm{~K}$ and $1400 \mathrm{~K}$ on the turbulent mixing process are expected to be relatively small and therefore the physical delay and its associated variability should remain approximately constant. In contrast, it is well established that the kinetic delay is substantially decreased by increasing temperature in this range under diesel or gas-turbine engine conditions of pressure (Bowman, 1970; Bi and Agrawal,1998; Peterson et al., 2007; Huang et al., 2004, 2006). As the kinetic delay decreases, so the magnitude of the variation in the kinetic delay will also decrease. Accordingly, the scatter in the experimental data should be expected to decrease at higher pre-combustion temperatures as the auto-ignition process becomes mainly "mixinglimited". 
Although the results shown in Figure $3 a$ are characterized by significant scatter, and therefore accepting that these experimental data should be used with considerable care, it is interesting to compare and contrast the trends shown in the figure with those found in literature data. Assuming the auto-ignition process to be similar to that of a premixed homogeneous system in which a single-step reaction occurs, the experimental data shown in Figure 3a were fitted to:

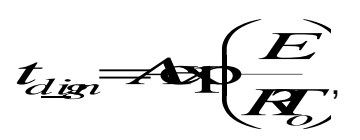

where $E$ is the global activation energy and $R$ is the universal gas constant. The results of this fit, shown in Table 6, at first glance suggests that the global activation energy of methane, which for a given pressure is essentially a measurement of the temperature dependence of the ignition delay time (there is also a weaker concentration dependence), decreases with the addition of $20 \% \mathrm{H}_{2}$. However, the interpretation of this result is complicated by the previously discussed change in the limiting ignition mechanism (kinetic or physical) with temperature of the nonpremixed jet in the shock tube experiments, and, although Herzler and Naumann (2009) do report a reduction in global activation energy for a premixed methane/ethane/hydrogen blend containing $40 \%$ by volume $\mathrm{H}_{2}$, further consideration of the literature data and comparison with the results of the FlameMaster simulation shown in Figure $3 b$ suggest that observed result is dominated by other factors.

Table 6: Least-squares fitting results for $t_{d \_i g n}$ and $T_{0}$

\begin{tabular}{|c|c|c|c|}
\hline Fuel $-\% \mathrm{H}_{2}$ by volume & $\mathrm{A}(\mathrm{ms})$ & $\mathrm{E}(\mathrm{kcal} / \mathrm{mol})$ & $\mathrm{R}^{2}$ \\
\hline 0 & 0.0010 & 17.1 & 0.6924 \\
\hline 20 & 0.0124 & 10.4 & 0.4232 \\
\hline
\end{tabular}

In a shock tube study of ignition in premixed fuel/oxidizer systems, Petersen et al. (2007) reported that there were no significant differences between the global activation energies of methane and of a $80 / 20$ ( $\%$ by volume) blend of methane and hydrogen-although faster ignition was noted with the addition of hydrogen. Petersen and co-workers attributed the reduction in ignition delay to the addition of additional, favourable, radicals to the pre-ignition radical pool. 
Thus, Peterson's work is in strong agreement with the earlier work of Huang et al. (2006) who concluded that hydrogen addition does not change the main reaction path of the methane system - and therefore that the effect of hydrogen on methane ignition is primarily related to the generation and consumption of reactive radicals including $\mathrm{CH}_{3}, \mathrm{H}, \mathrm{OH}$, and $\mathrm{HO}_{2}$. The FlameMaster simulations shown in Figure $3 b$ show that the ignition delay decreases with hydrogen addition over the temperature range studied (in agreement with the experimental data) but, in contrast to the shock tube results, do not suggest that the activation energy of the base methane fuel is notably reduced by the addition of $20 \%$ Hydrogen. Furthermore, as also seen by comparing the numerical and experimental results presented in Tables 4 and 5 respectively, the predicted ignition delay times are consistently and substantially shorter than those measured in the shock tube experiments. In many ways this is to be expected.

The simulated combustion configuration, a non-premixed counterflow diffusion flame, is clearly a very different combustion configuration to that of the shock tube experiments, in which turbulent gaseous fuel is injected into heated and compressed air. Accordingly, we do not expect that the FlameMaster simulations will exactly match the shock tube data-either in magnitude or in exact behaviour. For example, whereas the ignition delay in the shock tube is composed of a chemical kinetic delay and a physical delay associated with turbulent mixing, the ignition delay in the simulations is composed of a chemical kinetic delay and a physical delay due to diffusion (where the chemical kinetic delay is expected to dominate). However, we do believe that comparison of the numerical and experimental results while giving due consideration to the differences between the two combustion configurations can provide valuable insight into the effects of hydrogen addition on the ignition and combustion of non-premixed turbulent natural gas (or methane) jets.

Reconsidering then the shock tube data (Figure 3a) in light of the knowledge gained from the FlameMaster simulation (Figure $3 b$ ) leads to the following interpretation of the experimental results. The potential of hydrogen to enhance ignition in high-pressure non-premixed natural gas combustion systems is highly dependent on the pre-combustion temperature. At the lower end of the temperature range examined in this work, the ignition delay is substantially reduced by the 
addition of $20 \%$ hydrogen. The FlameMaster simulations shown in Figure 4 suggest, in agreement with the previous works of Huang et al. (2006) and Petersen et al. (2007), that under these conditions the addition of hydrogen enhances ignition through changes to the chemical kinetics. The figure shows the predicted mass fraction profiles of the $\mathrm{CH}_{3}, \mathrm{H}, \mathrm{OH}$, and $\mathrm{HO}_{2}$ radicals at a stoichiometric mixture fraction $\left(Z_{s t}\right)$ for different methane/hydrogen blends. The addition of hydrogen is predicted to cause the peaks of $\mathrm{CH}_{3}, \mathrm{H}, \mathrm{OH}$, and $\mathrm{HO}_{2}$ mass fraction to move earlier in time. Moreover, when the hydrogen concentration increases, a more rapid rise in mass fraction is observed. These effects all contribute to accelerated methane oxidation, which results in a shorter ignition delay. At the higher end of the temperature range however, the experimental results show no significant difference in ignition delay between the $0 \%$ and the $20 \%$ hydrogen fuels suggesting that ignition is mixing-limited under these conditions.

\subsubsection{Ignition Kernel Location}

In this study, an ignition kernel is defined as the emergence of a non-contiguous new flame region not generated by the propagation of an existing flame. The location of an ignition kernel relative to the injector tip was identified from the high-speed video images-where the distance from the injector tip to the nearest (closest downstream) ignition kernel is defined as $Z_{k}$. Figure 5 shows a typical example image with $Z_{k}$ indicated. To account for the variation in fuel mass flux with injector orifice diameter $(d)$ and fuel/oxidizer pressure ratio $\left(P_{i} / P_{o}\right), Z_{k}$ is normalized such that

$$
Z_{k}^{*}=Z_{k} / d^{*}
$$

where $d^{*}=d \sqrt{P_{i} / P_{o}}$ as discussed by Hill and Ouellette (1999) and Rubas et al. (1998). Table 7 summarizes the normalized ignition kernel location data at fixed pre-combustion temperature and pressure (respectively $1300 \mathrm{~K}$ and $30 \mathrm{bar}$ ). Uncertainty in $Z_{k}$ is estimated to be approximately 1 $\mathrm{mm}$ (5 pixel widths) due to camera spatial and temporal resolution. After normalization, the uncertainty in $Z_{k}{ }^{*}$ is approximately $2 \%$, mainly due to the uncertainty in the pre-combustion pressure. 
Table 7: Summary of shock tube variability in $Z_{k}{ }^{*}$ data at pre-combustion temperature and pressure of $1300 \mathrm{~K}$ and 30 bar (20 repeat tests)

\begin{tabular}{|c|c|c|c|c|c|}
\hline Fuel $-\% \mathrm{H}_{2}$ by volume & Min $(\mathrm{mm})$ & Max $(\mathrm{mm})$ & Mean $(\mathrm{mm})$ & Std Dev & COV \\
\hline 0 & 18 & 54 & 32 & 8 & $26 \%$ \\
\hline 20 & 16 & 53 & 31 & 11 & $35 \%$ \\
\hline
\end{tabular}

The results shown in Table 7 demonstrate that addition of $20 \%$ hydrogen to the methane fuel has a negligible effect on $Z_{k}{ }^{*}$; an ANOVA analysis confirming that any minor differences are not statistically significant at any meaningful level $(P$-value $=0.690)$. It is, however, interesting to note the COV of $Z_{k}{ }^{*}$ increases from $26 \%$ to $35 \%$ with the addition of hydrogen to the fuel, i.e. the spatial variability of the auto-ignition event in the shock tube increases with hydrogen addition.

\subsubsection{Pollutant Emissions (Shock Tube and Modelling Results)}

\subsubsection{1 $\mathrm{NO}_{\mathrm{x}}$ Emissions}

To facilitate comparison between experiments with different fuel injection masses all of the $\mathrm{NO}_{\mathrm{x}}$ results presented in this work (shock tube and engine) are normalized by the total quantity of energy in the injected fuel mass. Table 8 summarizes the variability in normalized $\mathrm{NO}_{\mathrm{x}}$ data from the shock tube experiments at pre-combustion temperature and pressure of $1300 \mathrm{~K}$ and 30 bar. Error in the normalized $\mathrm{NO}_{\mathrm{x}}$ emissions is estimated at $\sim 5 \%$, mainly due to the uncertainty in the amount of fuel injected per shot. Under these conditions, the addition of $20 \%$ hydrogen to the methane base fuel is seen to cause a substantial decrease in $\mathrm{NO}_{\mathrm{x}}$ production. The results shown in Table 8 indicate that there is a $48 \%$ reduction in the mean $\mathrm{NO}_{\mathrm{x}}$ level due to the two fuels. An ANOVA analysis confirms this result as statistically significant with a $P$ value of 0.0 . A substantial decrease (33\%) in $\mathrm{NO}_{\mathrm{x}}$ emissions variability is also observed.

Table 8: Summary of shock tube variability in normalized $\mathrm{NO}_{x}$ data at pre-combustion temperature and pressure of $1300 \mathrm{~K}$ and 30 bar (20 repeat tests)

\begin{tabular}{|c|c|c|c|c|c|}
\hline Fuel - $\% \mathrm{H}_{2}$ by volume & $\begin{array}{c}\text { Min } \\
\left(\mathrm{g} / \mathrm{MJ}_{\text {FUEL }}\right)\end{array}$ & $\begin{array}{c}\text { Max } \\
\left(\mathrm{g} / \mathrm{MJ}_{\text {FUEL }}\right)\end{array}$ & $\begin{array}{c}\text { Mean } \\
\left(\mathrm{g} / \mathrm{MJ}_{\mathrm{FUEL}}\right)\end{array}$ & $\begin{array}{c}\text { Std Dev } \\
\left(\mathrm{g} / \mathrm{MJ} \mathrm{FUEL}_{\mathrm{FUE}}\right)\end{array}$ & COV \\
\hline 0 & 0.47 & 1.18 & 0.91 & 0.19 & $21 \%$ \\
\hline 20 & 0.35 & 0.61 & 0.47 & 0.07 & $14 \%$ \\
\hline
\end{tabular}


Figure 6 shows the variation of the normalized $\mathrm{NO}_{\mathrm{x}}$ emissions with the shock tube precombustion temperature for both the $0 \%$ and the $20 \%$ hydrogen fuels. As expected, $\mathrm{NO}_{\mathrm{x}}$ emissions increase with increasing pre-combustion temperature for both fuels. Interestingly, the data shows the addition of $20 \%$ hydrogen to lower the average normalized $\mathrm{NO}_{\mathrm{x}}$ emissions by similarly significant amounts (on a \% basis) across the full pre-combustion temperature range examined in the shock tube study (1200-1400 K).

With respect to the mechanism by which the addition of $20 \%$ hydrogen brings about the observed reduction in shock tube $\mathrm{NO}_{\mathrm{x}}$ emissions compared to the base methane fuel, it is instructive to consider the adiabatic flame temperature data presented in Table 9.

Table 9: Calculated adiabatic flame temperatures, $T_{\text {ad }}$, for methane/hydrogen fuel blends at different volumetric air-fuel ratios (Fuel temperature $300 \mathrm{~K}$, oxidizer temperature $1300 \mathrm{~K}$, pressure 30 bar)

\begin{tabular}{|c|c|c|c|c|c|c|}
\hline & \multicolumn{2}{|c|}{ Stoichiometric $(\Phi=1)$} & \multicolumn{2}{c|}{ Air/Fuel=10 (mol/mol) } & \multicolumn{2}{c|}{ Air/Fuel=20 (mol/mol) } \\
\hline $\begin{array}{c}\text { Fuel - \% } \mathrm{H}_{2} \text { by } \\
\text { volume }\end{array}$ & Air/Fuel $(\mathrm{mol} / \mathrm{mol})$ & $\mathrm{T}_{\text {ad }}(\mathrm{K})$ & $\Phi$ & $\mathrm{T}_{\text {ad }}(\mathrm{K})$ & $\Phi$ & $\mathrm{T}_{\text {ad }}(\mathrm{K})$ \\
\hline 0 & & & & & & \\
\hline 20 & 9.5 & 2774 & 0.95 & 2752 & 0.48 & 2204 \\
\hline
\end{tabular}

The table shows the adiabatic flame temperatures for a stoichiometric reaction and for two different molar air-fuel ratios for the both fuels calculated using the chemical equilibrium package Gaseq (Morley, n.d.). A fuel temperature of $300 \mathrm{~K}$ and an oxidizer temperature of $1300 \mathrm{~K}$ were used in the calculation. The pressure was fixed at 30 bar to match the nominal value of the shock tube experiments. It can be seen that under stoichiometric conditions the adiabatic flame temperature of the methane/hydrogen blend is very slightly $(8 \mathrm{~K})$ higher than that for pure methane. However under lean conditions, the adiabatic flame temperature of the $20 \%$ hydrogen fuel is markedly lower $(>100 \mathrm{~K})$ than that of the pure methane. The results shown in Table 9 therefore suggest that the reduction in $\mathrm{NO}_{x}$ emissions that is observed in the shock tube studies with the addition of $20 \%$ hydrogen to the fuel may be due to a shift in the reaction zone fueloxidizer stoichiometry (the addition of hydrogen promoting combustion at a leaner AFR). 


\subsection{Applied Combustion Study (Pilot-Ignited Direct-Injection Natural Gas IC Engine)}

The addition of hydrogen to the fuel has a significant influence on the combustion process and especially on the emissions of a pilot ignition, direct-injection of natural gas engine. These results have been published in more detail elsewhere (McTaggart-Cowan et al., 2009). The material presented here will focus on the ignition, early combustion stability, and $\mathrm{NO}_{\mathrm{x}}$ formation influences of fuel composition, allowing direct comparison with the shock tube and modeling work presented above. Experimental uncertainty in the engine work is presented as the $95 \%$ confidence intervals based on the repeatability of the results at equivalent operating conditions on fuel blends reported in previous work (McTaggart-Cowan et al. 2008). Before discussing these results however, it is useful to review the similarities and differences between the combustion systems of the pilot ignited direct-injection engine and the high-pressure shock tube.

Whereas the charge into which the fuel is injected in the shock tube is quiescent with constant temperature and pressure, the charge in the engine is highly turbulent with both small and large-scale turbulence present due to breakdown of the bulk motion induced by the induction process. Furthermore, in the engine, the temperature and pressure of the charge vary as the piston moves-although this effect is relatively small in the region of interest (the piston motion is only $4 \%$ of the total stroke length over the $20^{\circ} \mathrm{CA}$ before or after TDC). Perhaps most significantly, whereas the gaseous fuel in the shock tube auto-ignites in the high temperature oxidizer, a diesel pilot flame promotes ignition in the engine. The pilot flame is believed both to provide heat, which will enhance reaction rates, and also to generate a pool of radicals that may help advance the ignition process. However, which of these two effects is dominant in the engine is presently unclear.

\subsubsection{Ignition Delay (Gaseous Fuel)}

Identifying the specific time for start-of-combustion (SOC) of the gaseous fuel is difficult in this pilot-ignited, direct injection of natural gas dual fuel engine, as the preceding pilot combustion gradually transitions into the gaseous fuel combustion process. In this study therefore, to provide a consistent method of identifying the effects of hydrogen addition on the gaseous ignition delay (GID) we assume that the gaseous fuel SOC occurs at the $10 \%$ Integrated Heat Release (IHR) 
point, i.e. the point within the cycle (measured in degrees crank angle) at which $10 \%$ of the total fuel energy has been released. While this metric does not necessarily coincide with the gaseous fuel start-of-combustion, the trends with combustion timing and fuel composition should be consistent between start-of-combustion and the $10 \%$ IHR point. The GID is therefore defined as the time interval between the commanded start of injection of the gaseous fuel (GSOI) and the $10 \%$ IHR point.

Figure 7 shows that adding hydrogen to the fuel has a small but significant impact on the heat release rate. IHR data for all three fuels are shown at an intermediate combustion timing ( $50 \%$ IHR at $10^{\circ}$ ATDC); note that similar results are observed at all other timings examined. In general, the IHR data demonstrate that the bulk of the combustion occurs at a similar rate for all three gaseous fuels. However, a more detailed analysis of the IHR data shows that the gaseous ignition delay is shorter with hydrogen in the fuel. Following ignition, the initial combustion rate of the hydrogen-blended fuels in the engine is slower than that with no hydrogen addition, as shown by the lower slope of the IHR profile for the early stages of the combustion event. This is an interesting result since the slower combustion rate occurs despite the predicted increase in the concentration of reactive radicals in the reaction zone that was suggested by the FlameMaster simulation. The slower initial combustion rate of the hydrogen containing fuels in the engine may be explained, in part, by the lower energy density of the hydrogen-blended fuels (see Table 3) meaning that there is inherently less chemical energy available at a combustible stoichiometry in the early stages of the combustion. This effect would be exacerbated by the shorter ignition delay time with the hydrogen-blended fuel, as a shorter ignition delay provides less time for the gaseous fuel to mix to a combustible stoichiometry before ignition. Accordingly, the experimental results suggest that the early-stage combustion processes in the engine are most sensitive to the rate at which fuel and oxidizer are mixing.

The effect of hydrogen addition on the delay between commanded start-of-injection for the gaseous fuel (GSOI) and the $10 \% \mathrm{IHR}$ is shown in Figure 8 , along with the cycle-to-cycle variability in the $10 \% \mathrm{IHR}$ timing. The ignition delay data is based on the average heat-release rate calculated from 50 consecutive engine cycles, while the cycle-to-cycle variability in the 
combustion is determined by evaluating the individual heat-release rates for the same 50 cycles. The results are plotted against the temperature at the start of the pilot injection, calculated assuming a polytropic compression with an exponent of 1.36-a value determined from experimental pressure-volume data recorded during the engine's compression stroke. In general, more advanced combustion phasing resulted in earlier injection and hence lower pre-combustion temperatures.

The left-hand graph in Figure 8 demonstrates that the ignition delay of the gaseous fuel in the engine is substantially reduced by the addition of hydrogen (decreases of approximately $10 \%$ with $15 \% \mathrm{H}_{2}$ in the fuel and $20 \%$ with $35 \% \mathrm{H}_{2}$ in the fuel are shown). Similar reductions are found for the full range of start of injection temperatures examined. It is interesting to contrast this behaviour with that previously observed in the shock tube. Analysis of the shock tube data, supported by the results of the FlameMaster simulations (§6.1.1), showed that the potential of hydrogen to enhance ignition in high-pressure non-premixed natural gas combustion systems is temperature dependent. At higher temperatures, the influence of the fuel composition on ignition delay was found to be negligible; this suggests that, under these high-temperature conditions, the ignition process appears to be mixing-limited. However, temperatures in the engine at the end of the compression stroke are relatively low, compared to the shock tube cases. The slow combustion of the pilot fuel, which amounted to less than $5 \%$ of the total fuel energy, will not increase the bulk in-cylinder temperature to the levels seen in the shock tube. As a result, the shock tube results that are most pertinent to the engine conditions are those for the lower preignition temperatures, where the chemical kinetics are relatively more important. In these situations, the shock tube work demonstrates (Figure 4) that the addition of hydrogen was found to decrease the ignition delay time. The Flamemaster simulations suggest that the addition of hydrogen to methane promotes ignition through changes to the pre-ignition radical pool. In this low-temperature - kinetically dominated - ignition regime, the modelling results (and literature data of premixed methane/hydrogen combustion) show an increasing reduction in ignition delay time with increasing hydrogen content.

In light of the above, the reduction in the gaseous ignition delay shown in Figure 8 seems 
to suggest that ignition of the gaseous fuel jet in the engine occurs within a temperature range in which chemical kinetics play a significant role in determining the ignition delay, i.e. at lower temperatures than those that cause the ignition of the fuel jet to become mixing-limited. The relative importance of the chemical kinetic delay compared to the physical delay in the engine application is further emphasized by considering that the air-fuel mixing process in the engine is enhanced by the in-cylinder turbulence of the charge compared to the quiescent environment of the shock tube. Accordingly, the physical delay time, and its contribution to the overall ignition delay in the engine, is expected to be reduced.

\subsubsection{Cycle-to-Cycle Variability of the Ignition Delay}

The right-hand graph in Figure 8 indicates that cycle-to-cycle variability of the gaseous ignition delay in the pilot-ignited engine is significantly reduced by the addition of hydrogen to the fuel. Simultaneously, the ignition delay is reduced as discussed in $§ 6.2 .1$. The improvement in ignition stability with hydrogen addition seen in the engine is not found in the shock tube experiments in which the temporal variability of ignition is almost unchanged by the addition of hydrogen.

One possible explanation for the improved ignition stability in the engine is that hydrogen addition increases the number of ignitable regions in the transient gaseous jet due to the wider ignition and flammability limits of the hydrogen-blended fuels. This hypothesis is consistent with the observations of increased variability in the location of the ignition kernel with hydrogen addition in the shock tube studies (§6.1.2). A greater number of ignitable regions in the fuel jet would increase the probability of an ignitable region being exposed to the localized temperature and radical pool generated by the pilot flame. In turn, this would lead to the reduced ignition delay time and improved stability observed in the engine.

\subsubsection{Pollutant Emissions (Engine Results)}

The presence of hydrogen in the fuel has a substantial impact on pollutant formation in the engine. Direct influences on the pollutant-formation chemistry are confounded with the effects of hydrogen on the ignition and combustion event. Given the complexity of the combustion and pollutant formation processes, it is very difficult to identify causal relationships between the early 
phases of the combustion event, the fuel blend, and measured engine out pollutant levels. The two emissions that are, in general, more sensitive to variations in the ignition process are $\mathrm{NO}_{\mathrm{x}}$ and hydrocarbons (primarily unburned methane). The engine-out emissions of these species, normalized by the total quantity of energy in the fuel, are shown in Figure 9.

\section{$N O_{x}$ Emissions}

The left-hand graph in Figure 9 shows that $\mathrm{NO}_{x}$ emissions from the engine (normalized with respect to the energy content of the injected mass of fuel) are slightly increased with hydrogen addition, although the effect is only greater than the experimental uncertainty with $35 \%$ $\mathrm{H}_{2}$ in the fuel. Combustion timing, because of its influence on the reaction zone temperature, has a much more significant influence. Interestingly, the effect of $\mathrm{H}_{2}$ addition is greater at lower incylinder temperatures; at the higher temperatures associated with later combustion timing, there is no apparent influence of hydrogen content on $\mathrm{NO}_{\mathrm{x}}$ emissions.

As Table 9 demonstrated, the adiabatic flame temperature of the gaseous fuel is relatively insensitive to hydrogen content for a given stoichiometry. Since the engine-out $\mathrm{NO}_{\mathrm{x}}$ emissions are expected to be dominated by thermal production mechanisms, the fact that hydrogen addition results in higher engine-out $\mathrm{NO}_{x}$ emissions suggests that the stoichiometry of the reaction zone in the engine is not changing substantially (or is even enriched slightly) with the addition of hydrogen to the fuel. Note that the authors recognize also that there are possible interactions between the hydrogen radicals and the $\mathrm{NO}_{\mathrm{x}}$ formation chemistry; however, these potential influences require further fundamental chemical investigations and are beyond the scope of the present study.

It is insightful to consider the engine results presented above in comparison with the shock tube results described in $\$ 6.1 .3 .1$, in which the addition of $20 \%$ hydrogen to the fuel caused a substantial ( $50 \%$ ) decrease in normalized $\mathrm{NO}_{\mathrm{x}}$ emissions. This was attributed to a shift in the reaction zone fuel-oxidizer stoichiometry (the addition of hydrogen promoting combustion at a leaner AFR in the shock tube). Conversely, in the engine, the increase in NOx emissions with $35 \% \mathrm{H}_{2}$ suggests that the mixture fraction in the reaction zones where $\mathrm{NO}_{x}$ is being formed is, if 
anything, richer than for the natural gas cases. This agrees with the earlier observation that the shorter ignition delay resulted in less gaseous fuel being burned in the initial reaction stages, potentially leaving a larger premixed reaction and hence, potentially, a richer reaction with a longer residence time before the local post-combustion gases are quenched, terminating the NO formation process. It is important to recall that the NO formation mechanisms are a function of both temperature and time; the more intense turbulence in the engine, and hence presumably shorter time before the burned gases are quenched, could lead to NO formation that is much farther from equilibrium than for the shock-tube case. Further research is needed to develop an improved understanding of the similarities, and differences, in NO formation for these two combustion systems.

HC Emissions

The emissions of unburned hydrocarbons (shown in the right-hand graph of Figure 9) show a substantial reduction with hydrogen addition to the fuel. This may be a result of a number of factors, including the shorter ignition delay time and wider flammability range of hydrogencontaining fuels leading to less fuel having mixed beyond the combustible limit prior to ignition. It is also likely that the hydrogen in the fuel is helping to resist local extinction due to turbulent shear, and may also be delaying bulk extinction of the late-combustion zone reactions. Unfortunately, the available information is insufficient to identify which of these effects may be dominant.

\section{Conclusions}

As the above sections demonstrate, there are substantial differences in the influences of gaseous fuel composition on the results from the two experimental non-premixed combustion systems. However, both the similarities and the differences provide valuable insight into the nonpremixed combustion of natural gas under conditions representative of those in an internal combustion engine. From the presented results we conclude that:

1) Ignition in the pilot-ignited direct-injection natural gas engine is kinetically limited under the full 
range of conditions examined.

2) The limiting ignition mechanism in the shock tube experiments is temperature dependant; being mixing limited at high pre-combustion temperatures while being dominated by chemical kinetic effects at lower values of pre-combustion temperature.

3) The effects of hydrogen addition on ignition delay vary according to the limiting ignition mechanism of the application. Where ignition is dominated by chemical kinetic concerns, such as in the engine or the shock tube at low pre-combustion temperatures, the addition of hydrogen to the fuel reduces the ignition delay time. The results of this study further suggest, in agreement with the literature, that the observed reduction in ignition delay is due to earlier formation of reactive radicals (such as $\mathrm{H}, \mathrm{OH}$, etc.) in the pre-ignition stage. Where ignition is mixing-limited, such as in the shock tube at higher pre-combustion temperatures, the effect of hydrogen addition on ignition is negligible.

4) The stability of ignition delay in the engine is improved with hydrogen addition. Based upon the results of our shock tube studies, we hypothesise that this is caused by an increase in the number of ignitable regions in the transient gaseous jet due to the wider ignition and flammability limits of the hydrogen-blended fuels. The probability of an ignitable region of the jet being exposed to the localized temperature and radical pool generated by the diesel pilot flame in the engine, and therefore the probability of ignition, is increased accordingly.

5) The effects of hydrogen addition on $\mathrm{NO}_{x}$ emissions vary according to the application. Lower $\mathrm{NO}_{\mathrm{x}}$ emissions from the shock tube results suggest that hydrogen is significantly lowering the fuel/air ratio, resulting in a leaner mixture in the reaction zone; however, higher engine-out $\mathrm{NO}_{\mathrm{x}}$ emissions suggests that the reaction zone stoichiometry in the engine application is relatively unchanged. 


\section{References}

Allenby, S., Chang, W-C., Megaritis, A. and Wyszynski, M.L. (2001) Hydrogen enrichment: a way to maintain combustion stability in a natural gas fuelled engine with exhaust gas recirculation, the potential of fuel reforming. Proceedings of the Institution of Mechanical Engineers, Part D. 215. Pp. 405-418.

Bauer, C.G. and Forest, T.W. (2001) Effect of hydrogen addition on the performance of methanefueled vehicles. Part I: effect on S.I. engine performance. Int. J. of Hydrogen Energy. 26. Pp. 5570.

Bi, H., Agrawal, A.K. (1998) Study of autoignition of natural gas in diesel environments using computational fluid dynamics with detailed chemical kinetics. Combustion and Flame. 113. Pp. 289-302.

Bowman, C.T. (1970) An experimental and analytical investigation of the high-temperature oxidation mechanisms of hydrocarbon fuels. Combustion Science and Technology. 2. Pp. 161172.

Cheng, A.K., Oppenheim, R.K. (1984) Autoignition in methane-hydrogen mixtures. Combustion and Flame. 58. Pp. 125-139.

Collier, K., Mulligan, N., Shin, D., and Brandon, S. (2005) Emission results from the new development of a dedicated hydrogen-enriched natural gas heavy duty engine. SAE Technical Paper 2005-01-0235.

Fotache, C.G., Kreutz, T.G. and Law, C.K. (1997) Ignition of hydrogen-enriched methane by heated air. Combustion and Flame. 110. Pp. 429-440.

Fraser, R.A, Siebers, D.L., and Edwards, C.F. (1991) Autoignition of methane and natural gas in a simulated diesel environment, SAE Technical paper 910227.

Frisque, A., Schnakenberg, J., Huang, J., and Bushe, W.K. (2006) Stochastic simulation of the variations in the autoignition delay time of premixed methane and air. Combustion Theory and Modelling. 10. pp. 241-256.

Gauducheau, J.L., Denet, B. and Searby, G. (1998) A numerical study of lean $\mathrm{CH}_{4} / \mathrm{H}_{2} /$ air premixed flames at high pressure. Combustion Science and Technology. 137. Pp. 81-99.

Gauthier, B.M, Davidson, D.F., Hanson, R.K. (2004) Shock tube determination of ignition delay times in full-blend and surrogate fuel mixtures, Combustion and Flame. 139, pp. 300-311.

Gaydon, A.G., and Hurle, I.R. (1963) The Shock Tube in High Temperature Chemical Physics, Chapman and Hall, London.

Gersen, S., Anikin, N.B., Mokhov, A.V., and Levinsky, H.B. (2008) Ignition Properties of Methane/Hyrogen Mixtures in a Rapid Compression Machine. Int. J. Hydrogen Energy. 33. Pp 1957-1964

Herzler, J., and Naumann, C. (2009) Shock-tube Study of the Ignition of Methane/Ethane/Hydrogen Mixtures with Hydrogen Contents from $0 \%$ to $100 \%$ at Different pressures. Proc. Combustion Institute. 32. Pp 213-220.

Hill, P. G., and Ouellette, P. (1999) Transient Turbulent gaseous fuel jets for diesel engines. ASME Journal of Fluids Engineering. 121. Pp. 93-101

Huang, J., Bushe, W.K., Hill, P.G., Munshi, S.R. (2006) Experimental and kinetic study of shock 
initiated ignition in homogeneous methane/hydrogen/air mixtures at engine-relevant conditions. International Journal of Chemical Kinetics. 38. Pp. 221-233.

Huang, J., Hill, P.G., Bushe, W.K., Munshi, S.R. (2004) Shock-tube study of methane ignition under engine-relevant conditions: experiments and modeling. Combustion and Flame. 136. Pp. $25-42$.

Karbasi, M. and Wierzba, I. (1998) The effects of hydrogen addition on the stability limits of methane jet diffusion flames. Int. J. Hydrogen Energy. 23. Pp. 123-129.

Karim, G.A., Wierzba, I. and Al-Alousi, Y. (1996) Methane-hydrogen mixtures as fuels. Int. J. Hydrogen Energy. 21. Pp. 625-631.

Kido, H., Nakahara, M., Hashimot, J. and Barat, D. (2002) Turbulent burning velocities of twocomponent fuel mixtures of methane, propane, and hydrogen. JSME International Journal, Series B. 45. Pp. 355-362.

Larsen, J.F. and Wallace, J.S. (1997) Comparison of emissions and efficiency of a turbocharged lean-burn natural gas and hythane-fueled engine. ASME J. of Engineering for Gas Turbines and Power. 119. Pp. 218-226.

Law, C.K. and Kwon, O.C. (2004) Effects of hydrocarbon substation on atmospheric hydrogen-air flame propagation. Int. J. Hydrogen Energy. 29. Pp. 867-879.

Lifshitz, A., Scheller, K., Burcat, A., Skinner, G.B. (1971) Shock-tube investigation of ignition in methane-oxygen-argon mixtures. Combustion and Flame. 16. Pp. 311-321.

McTaggart-Cowan, G.P., S.N. Rogak, S.R. Munshi, P.G. Hill and W.K. Bushe. (2009a). Combustion in a Heavy-Duty Direct-Injection Engine using Hydrogen-Methane Blend Fuels. International Journal of Engine Research. 10(1). Pp. 1-13.

McTaggart-Cowan, G.P., Wu, N., Bei, J., Davy, M, Rogak, S.N. and Bushe, W.K. (2009b). Effects of Fuel Composition on High-Pressure Non-Premixed Natural Gas Combustion. Combustion Science and Technology. 181(3). 397-416.

McTaggart-Cowan, G.P., Rogak, S.N., Hill, P.G., Munshi, S.R. and Bushe, W.K. (2008). The Effects of Fuel Dilution in a Natural-Gas Direct-Injection Engine. I.Mech.E. Part D, Journal of Automobile Engineering. 222. Pp. 441-454.

McTaggart-Cowan, G.P. (2006) "Pollutant Formation in a Gaseous-Fuelled, Direct-Injection engine". Ph.D. Thesis. University of British Columbia, Vancouver, Canada.

McTaggart-Cowan, G.P., Bushe, W.K., Hill, P.G. and Munshi, S.R. (2003) A supercharged singlecylinder heavy-duty engine for high pressure direct injection of natural gas. International Journal of Engine Research. 4(4). Pp. 315-330.

Morley, C. (n.d.) Gaseq: A Chemical Equilibrium Program for Windows. Available from: http://www.arcl02.dsl.pipex.com

Munshi, S.R., Nedelcu, C., Harris, J. (2004) Hydrogen blended natural gas operation of a heavy duty turbocharged lean burn spark ignition engine. SAE Technical Paper 2004-01-2956.

Naha, S. and Aggarwal, S.K. (2004) Fuel effects on NOx emissions in partially premixed flames. Combustion and Flame. 139. Pp. 90-105.

Petersen, E.L., Hall, J.M., Smith, S.D., de Vries, J., Amadio, A.R., and Crofton, M.W. (2007). 
Ignition of Lean Methane-Based Fuel Blends at Gas Turbine Pressures. Journal of Engineering for Gas Turbines and Power. 129. Pp 937-944.

Pitsch, H. Flamemaster v3.1: a $\mathrm{C}++$ computer program for 0D combustion and 1D laminar flame calculations. Available from http://www.stanford.edu/hpitsch

Rortveit, G.J., Zepter, K., Skreiberg, O., Fossum, M. and Hustad, J.E. (2002) A comparison of lowNOx burners for combustion of methane and hydrogen Mixtures. Proceedings of the Combustion Institute. 29. Pp. 1123-1129.

Rubas, P. J., Paul, M.A., Martin, G.C., Coverdill, R.E., Lucht, R.P., Peters, J.E. and DelVecchio, K.A. (1998) Methane jet penetration in a direct-injection natural gas engine. SAE Technical Paper 980143.

Schefer, R.W. (2003) Hydrogen enrichment for improved lean flame stability. Int. J. of Hydrogen Energy. 28. Pp. 1131-1141.

Sierens, R. and Rosseel, E. (2000) Variable composition hydrogen/natural gas mixtures for increased engine efficiency and decreased emissions. ASME J. of Engineering for Gas Turbines and Power. 122. Pp. 135-140.

Sullivan, G.D., Huang J., Bushe, W.K., and Rogak, S.N. (2006) Autoignition of transient turbulent gaseous fuel jets at high pressure. SAE Technical Paper 2006-01-3432.

Swain, M.R., Yusuf, M.J., Dulger, Z. and Swain, M.N. (1993) The effects of hydrogen addition on natural gas engine operation. SAE Technical Paper 932775.

Vasu, S.S., Davidson, D.F, Hanson, R.K. (2008) Jet fuel ignition delay times: Shock tube experiments over wide conditions and surrogate model predictions, Combustion and Flame. 152. pp. 125-143.

Wu, N. (2007) "Autoignition and Emission Characteristics of Gaseous Fuel Direct Injection Compression Ignition Combustion". Ph.D. Thesis. University of British Columbia. Vancouver, Canada.

Wu, N., Bushe, W.K.B., and Davy, M.H. (2010) On the experimental validation of combustion simulations in turbulent non-premixed jets. Submitted to Combustion Theory and Modeling. March 2010

\section{Figures}


QuickTime $^{\mathrm{TM}}$ and a

decompressor
are needed to see this picture.

Figure 1. Shock tube set-up

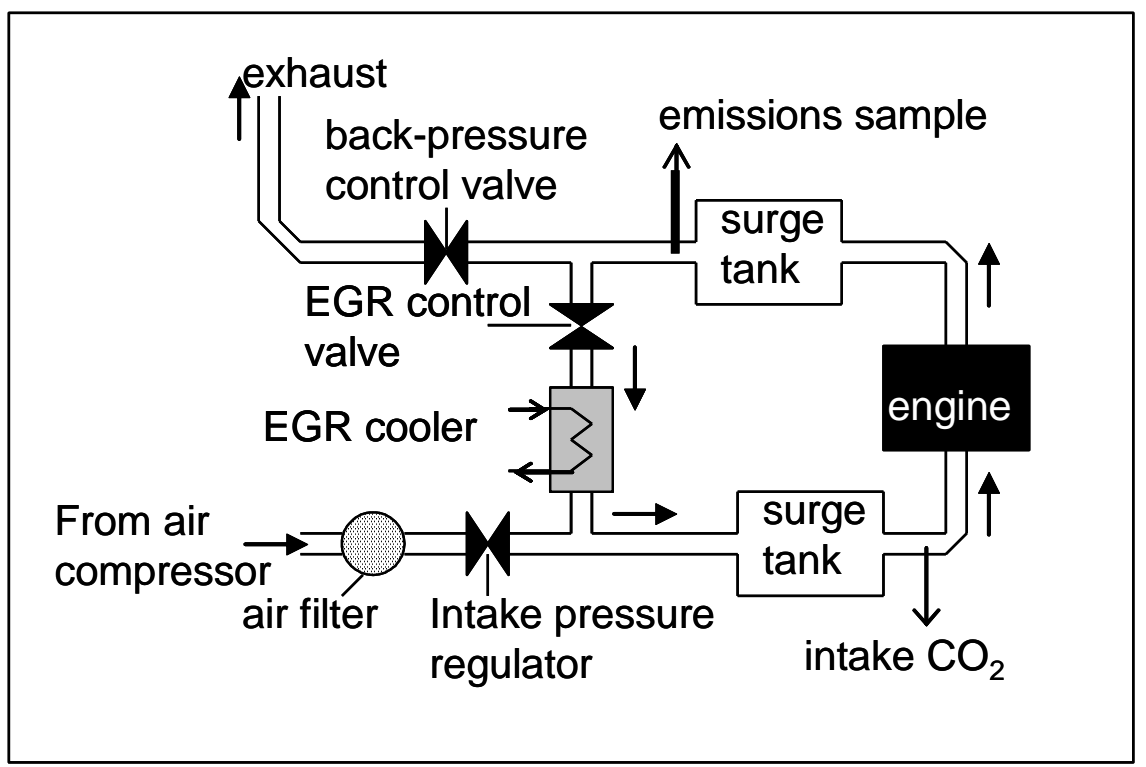

Figure 2. Schematic of engine test facility 


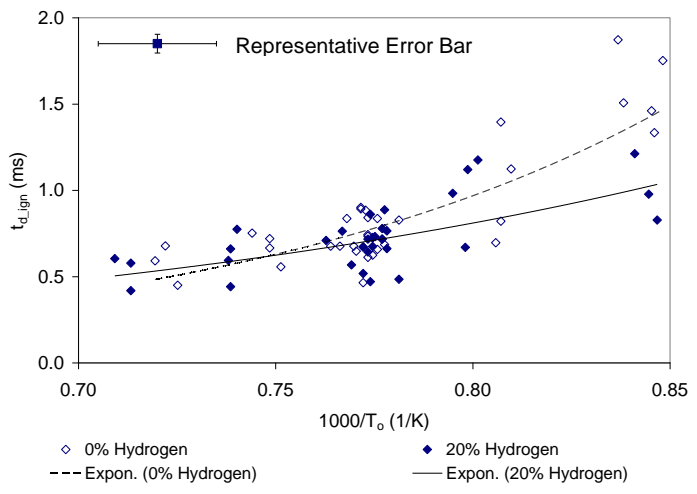

(a) Shock tube results

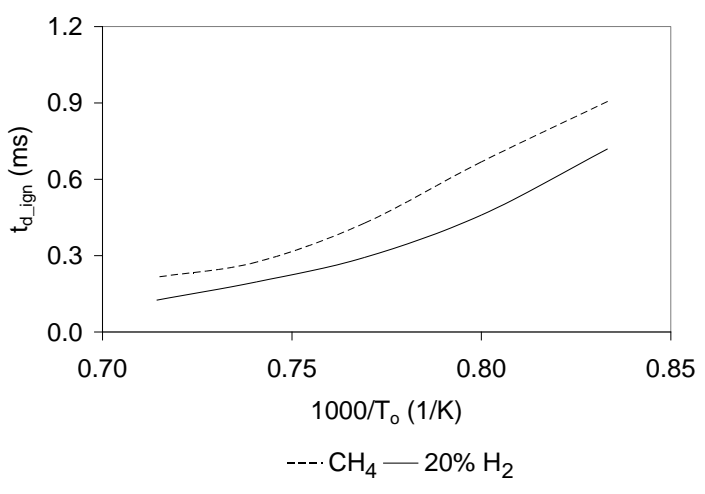

(b) FlameMaster results

Figure 3: Variation of ignition delay with pre-combustion temperature 

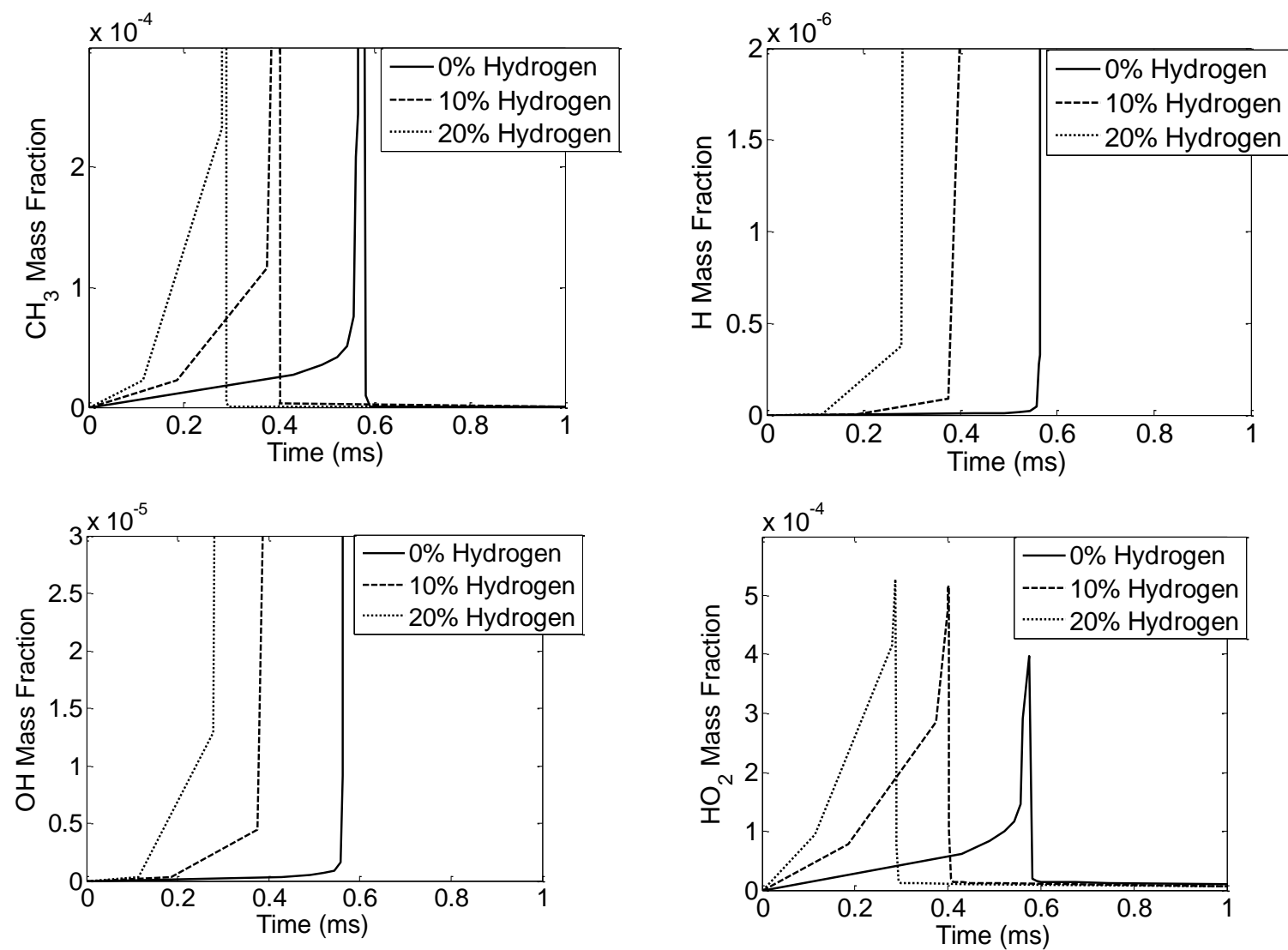

Figure 4: $\mathrm{CH}_{3}, \mathrm{H}, \mathrm{OH}$, and $\mathrm{HO}_{2}$ mass fraction history at $\mathrm{Z}_{\mathrm{st}}$ for methane/hydrogen blends (fuel temperature $300 \mathrm{~K}$, oxidizer temperature $1300 \mathrm{~K}$, pressure $30 \mathrm{bar}$ )

QuickTime $^{\mathrm{TM}}$ and a are needed to see this picture.

Figure 5: Typical CMOS camera image of ignition kernel (Image thresholding has been used to highlight the kernel in this image). 


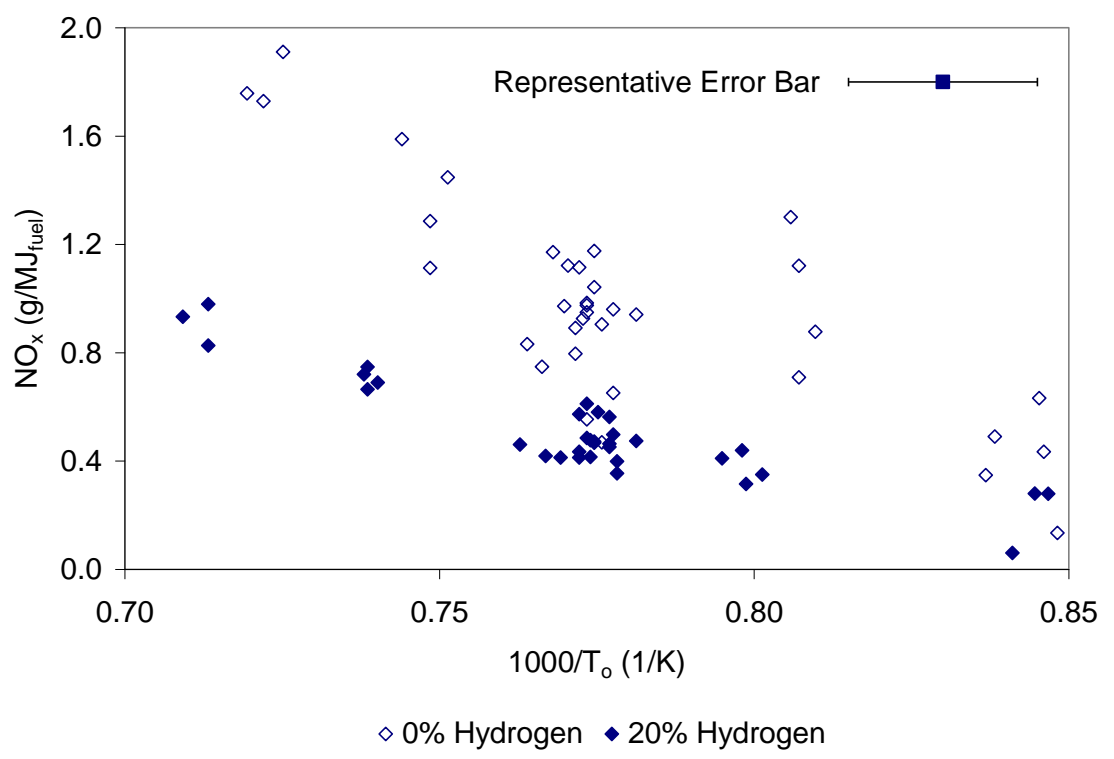

Figure 6: Normalized NOx emissions variation with pre-combustion temperature
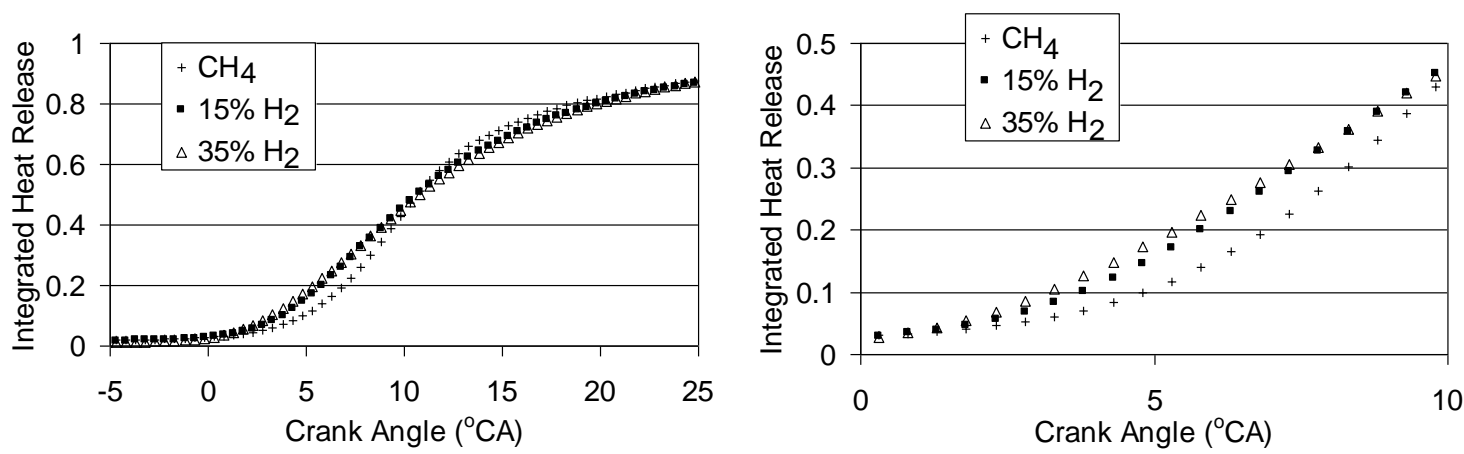

Figure 7: Effect of fuel composition on integrated heat release rate for the pilot-ignited engine. Plots are average of 50 cycles for each test point shown. Timing adjusted for $50 \% \mathrm{IHR}$ at $10^{\circ} \mathrm{CA}$.
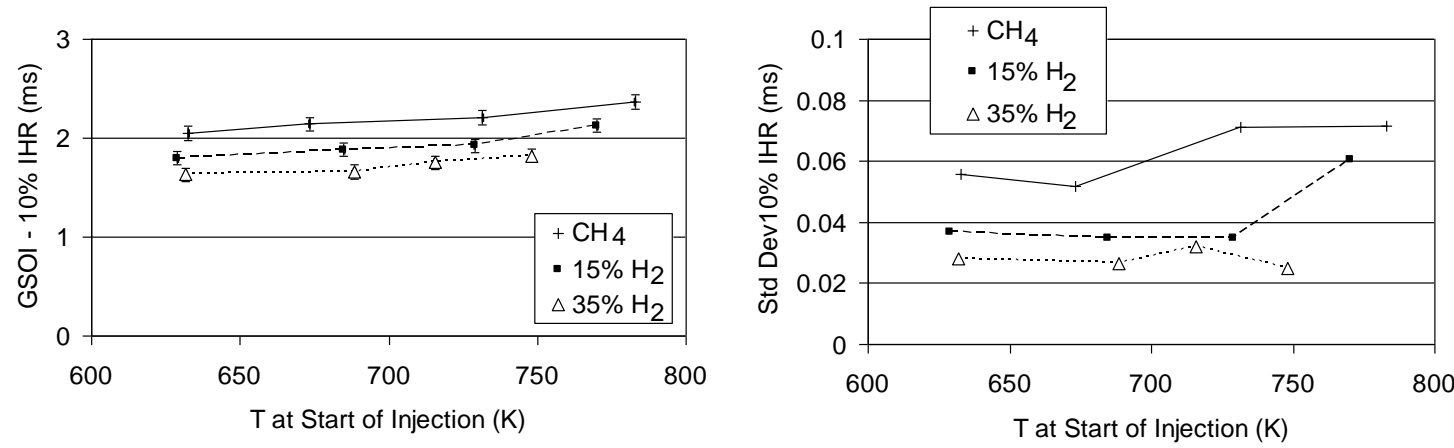

Figure 8: Effect of fuel composition on ignition delay as a function of in-cylinder temperature at the start of diesel injection. Ignition delay defined based on integrated heat release, stability on the cycle-to-cycle variability in the heat release rate. 

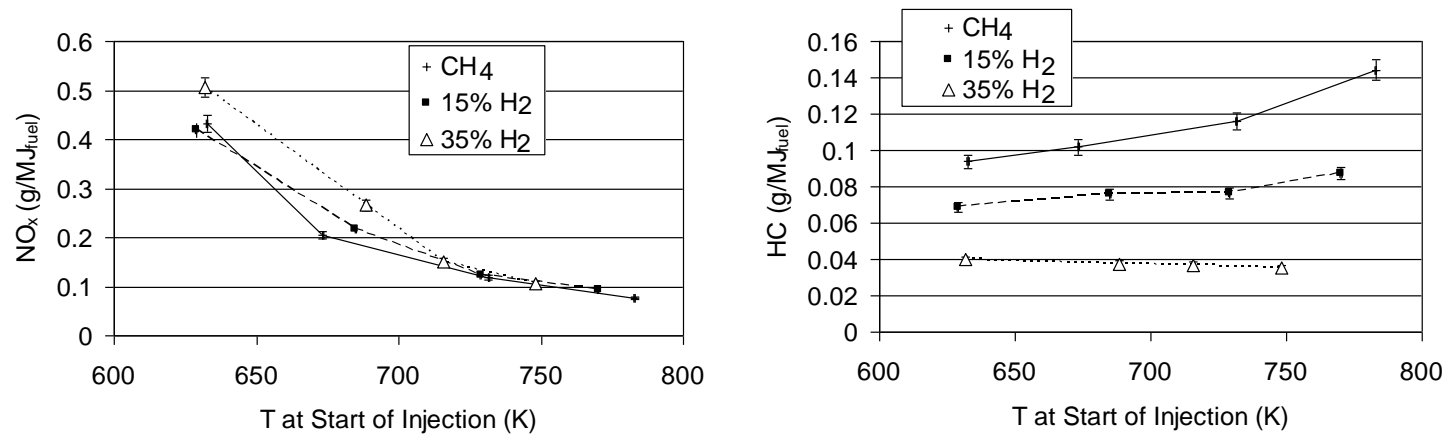

Figure 9: Effect of fuel composition on engine-out $\mathrm{NO}_{\mathrm{x}}$ and $\mathrm{HC}$ emissions as a function of incylinder temperature at the start of diesel injection. Emissions normalized by fuel energy content. 